Original Article

\title{
ASSESSMENT OF KNOWLEDGE OF ZIKA VIRUS INFECTION AMONG HEALTH CARE PROFESSIONALS IN A SOUTHEASTERN STATE OF NIGERIA
}

\author{
MAUREEN OGOCHUKWU AKUNNE ${ }^{*}$, UCHECHUKWU CHRIS CHUKWUEKEa, CHIBUEZE ANOSIKEa
}

\author{
aDepartment of Clinical Pharmacy and Pharmacy Management, Faculty of Pharmaceutical Sciences, University of Nigeria, 410001 Nsukka, \\ Enugu State, Nigeria \\ Email: maureen.akunne@unn.edu.ng \\ Received: 18 Sep 2017 Revised and Accepted: 21 Dec 2017
}

\begin{abstract}
Objective: Zika virus infection is fast becoming a major public health concern in both developed and developing countries of the world because of its association with microcephaly and Guillain Barre Syndrome. Assessment of its knowledge and understanding among different healthcare practitioners are essential for prevention and control especially in developing countries such as Nigeria. Our aim was to assess the knowledge of the virus and its associated factors among healthcare professionals (HCPs).

Methods: A cross-sectional study was conducted from June 10 to August 28, 2016, among health care professionals who were selected by nonprobability convenience sampling technique. The respondents were selected from various practice settings including academic institution, private and government hospitals in Enugu State, Nigeria. A validated and pilot tested 15 item questionnaire was used to evaluate respondents' knowledge of ZIKV infection. Descriptive statistics and chi-square were used to analyze respondents' level of knowledge and its associated factors using SPSS version 16.

Results: Two hundred (200) respondents participated in this study with more than half (53.0\%) being male, and most were either Physician or Pharmacist (59.5\%). Our results also showed that most of the respondents $(128,64.0 \%)$ had poor knowledge of ZIKV infection. However, among the respondents assessed, the Pharmacists and the Physicians had better knowledge of the disease as the test statistics were statistically significant at $\mathrm{X}^{2}=16.722$, $\mathrm{p}=0.033$. HCPs in the academia had better knowledge compared to those that are self-employed or practicing in private or government hospitals $\left(\mathrm{X}^{2}=17.178, \mathrm{p}=0.028\right)$.
\end{abstract}

Conclusion: Our findings suggest that most of the HCPs assessed in this study had poor knowledge of ZIKV infection. However, professional status, place of service, and study site were found to be associated with the respondents' level of knowledge. Hence, through sensitization and awareness campaigns through the media, seminars, and workshops aimed at educating HCPs on the disease should be encouraged.

Keywords: Zika virus, Zika infection, Knowledge, Health Care Professional, Nigeria

(c) 2018 The Authors. Published by Innovare Academic Sciences Pvt Ltd. This is an open access article under the CC BY license (http://creativecommons.org/licenses/by/4.0/) DOI: http://dx.doi.org/10.22159/ijpps.2018v10i2.22634

\section{INTRODUCTION}

Zika virus (ZIKV) infection has become a disease of global importance with its sporadic outbreaks from one region to another. ZIKV was originally identified in rhesus monkeys in the Zika forest of Uganda in 1947 [1]. Since ZIKV infection was reported in Uganda, there has been documented evidence of its occurrence in other African, Asian, and South American countries such as Nigeria, Senegal [2], Ivory Coast, Egypt, India, Malaysia, Philippine [3], Indonesia [4, 5] Colombia, and Brazil [6]. In all, as of May 2016, ZIKV infection has been reported in 58 countries and territories around the world, especially in the South Americas [7].

ZIKV is a Flavivirus transmitted by the bite of Aedes species of mosquitoes, especially Aedes aegypti [8, 9]. The transmission of ZIKV can also occur through sexual intercourse, as sexual transmission have been reported in Argentina, France, Chile, Italy, and New Zealand [10, 11]. Furthermore, ZIKV can equally spread by vertical transmission via mother-to-child transmission during pregnancy [12-14]. However, although ZIKV infection can be largely asymptomatic, its clinical presentations may include a headache, mild fever, arthralgia, conjunctivitis, myalgia, and cutaneous maculopapular rash [15].

ZIKV infection has been associated with microcephaly and GuillainBarre syndrome (GBS) in the newborn [16, 17]. Microcephaly is a disorder in which a newborn child has an abnormally developed head size much smaller in relation to babies of same sex and age. Head size is often used as an important parameter for monitoring brain growth in children. The clinical manifestations of microcephaly may vary from mild to severe and include intellectual disability, poor speech, seizures, swallowing problems, hearing, and sight abnormalities [18, 19]. However, its treatment is only symptomatic and supportive as there is no proven cure at present. On the other hand, GBS is a severe autoimmune disorder in which the body's immune system attack and destroy healthy nerve cells in the peripheral nervous system. Its clinical presentations include muscle weakness, numbness and tingling of body extremities, loss of bladder control, labored breathing, back pain, and ultimately paralysis $[20,21]$.

The first case of ZIKV infection was reported in Nigeria in a study conducted in 1968. The dreaded infection was also documented in some patients in the country between the period spanning 1971 to 1975. Nigeria is a developing country in West Africa with an estimated population of over 182 million people [22]. Nigeria is a high-risk country for ZIKV infection due to limited resources, overpopulation, and slow response by the government during times of disease outbreak. As the custodian of health, HCPs need to be well informed of the disease. In Nigeria, there is little or no study on the knowledge of HCPs regarding Zika virus infection especially pertaining to strategies for its prevention, clinical presentations, diagnosis, and possible treatment. Knowledge of ZIKV infection will enable HCPs to better handle the problem should the need arise. Therefore, this study aimed to assess the knowledge of ZIKV infection and its associated factors among Physicians, Pharmacists, Nurses, and Medical laboratory scientists practicing in some selected health care facilities and institution in Enugu state, Nigeria.

\section{MATERIALS AND METHODS}

\section{Study design}

A cross-sectional study was conducted to assess the knowledge of Zika virus infection among health care professionals in Enugu State, from June 10 to August 28, 2016. 


\section{Study setting}

The study was conducted in some selected health care facilities and a higher institution, both private and government-owned establishments. The facilities and institution used were the University of Nigeria Teaching Hospital (UNTH), Enugu State University Teaching Hospital (ESUTH), Bishop Shanahan Hospital (BSH), University of Nigeria Medical Center, University of Nigeria, Nsukka as well as some self-employed HCPs in Enugu State, Nigeria.

\section{Study population}

Two hundred respondents were randomly selected from the various study sites. The respondents included in the study were Physicians, Pharmacists, Nurses and Laboratory scientists who gave informed consent to participate in the study.

\section{Study instrument}

The instrument used for the study was developed by a team of experts on infectious disease management. The questionnaire items were obtained after careful and extensive literature search. The questions were based on the history, characteristics, symptomatology, transmission, diagnosis, complications, and treatment of Zika virus infection. Its face and content validity were assessed by experts in infectious disease management of the University of Nigeria Teaching Hospital, Ituku-Ozalla, Enugu State. Thereafter, irrelevant questions were removed while important but omitted items were added as required. A pilot study was conducted using 20 respondents from Enugu State University Teaching Hospital, Enugu State, who were not included in the actual study. Few adjustments were made were necessary after the pilot study as it was aimed at ensuring that the questions were clear, unambiguous, and comprehensive. The final questionnaire was divided into section A and section B. Section A contains respondents' demographic data such as gender, age, years of experience, professional status, and place of service, while section B contains 15 items assessing respondents' knowledge of ZIKV infection.

\section{Data collection}

The self-administered questionnaires for the study were distributed to the respondents at their place of work with the aid of trained research assistants. Strict measures were observed to ensure that none of the respondents was assisted in completing the questionnaire. The questionnaires were completed and returned almost immediately without delays.

\section{Ethical considerations}

Ethical approval was granted for this study by the Health Research Ethics Committee of the University of Nigeria Teaching Hospital, Ituku-Ozalla, Enugu State, Nigeria. The permission approval number is NHREC/05/01/2008B-FWA00002458-1RB00002323. Both oral and written consent was sought from the prospective participants. Only respondents who agreed to participate in the research were considered for selection. Strict confidentiality of respondents' information was maintained during and after data collection.

\section{Data analysis}

The respondents' demographic characteristics and level of knowledge were analyzed as frequencies and percentages. Chisquare was used to determine the association between demographic characteristics and level of knowledge. All statistical analysis was performed using SPSS version 16.

\section{RESULTS}

Out of the 248 questionnaires administered, 200 were returned giving a response rate of $80.6 \%$.

Table 1 showed that more than half $(53.0 \%)$ were male, and the majority were either Physicians or Pharmacists (59.5\%). As regard respondents' place of service, most of the healthcare professionals assessed were practising in government establishments (62.0\%), while majority work in a tertiary hospital (UNTH).

Table 1: The demographic characteristics of the study population

\begin{tabular}{|c|c|c|}
\hline Characteristics & Frequency & Percentage \\
\hline \multicolumn{3}{|l|}{ Gender } \\
\hline Male & 106 & 53.0 \\
\hline Female & 94 & 47.0 \\
\hline \multicolumn{3}{|l|}{ Age (Years) } \\
\hline $21-30$ & 37 & 18.5 \\
\hline $31-40$ & 62 & 31.0 \\
\hline $41-50$ & 59 & 29.5 \\
\hline $51-60$ & 36 & 18.0 \\
\hline$>60$ & 6 & 3.0 \\
\hline \multicolumn{3}{|l|}{ Professional status } \\
\hline Physician & 58 & 29.0 \\
\hline Pharmacist & 61 & 30.5 \\
\hline Nurse & 55 & 27.5 \\
\hline Laboratory Scientist & 24 & 12.0 \\
\hline \multicolumn{3}{|l|}{ Years of experience } \\
\hline $0-5$ & 61 & 30.5 \\
\hline $6-10$ & 43 & 21.5 \\
\hline $11-15$ & 41 & 20.5 \\
\hline$>15$ & 54 & 27.0 \\
\hline \multicolumn{3}{|l|}{ Place of service } \\
\hline Private Hospital & 38 & 19.0 \\
\hline Government & 124 & 62.0 \\
\hline Academics & 6 & 3.0 \\
\hline Self-employed & 28 & 14.0 \\
\hline Retired & 4 & 2.0 \\
\hline \multicolumn{3}{|l|}{ Study site } \\
\hline UNTH & 58 & 29.0 \\
\hline UNN & 6 & 3.0 \\
\hline UN Medical Center & 44 & 22.0 \\
\hline $\mathrm{BSH}$ & 37 & 18.5 \\
\hline ESUTH & 20 & 10.0 \\
\hline Self-employed & 35 & 17.5 \\
\hline
\end{tabular}




\section{Knowledge of zika virus infection}

It's true that greater percentage of the HCPs (75\%) knew that Zika infection is chiefly transmitted through mosquito bites, only a few $(13 \%)$ of them knew the symptoms of the disease. About $97.5 \%$ of the respondents could not give an example of an area with Zika outbreak. However, most of them knew that a pregnant woman with Zika infection can pass that to her unborn child causing serious birth defects. The questions and their responses for assessing knowledge of Zika Virus infection among HCPs are shown in table 2.

Table 2: Knowledge of zika virus infection among healthcare professionals

\begin{tabular}{|c|c|c|}
\hline Questions & Positive frequency (\%) & Negative frequency (\%) \\
\hline What type of virus is Zika? & $46(23)$ & $152(76)$ \\
\hline Do you know where Zika Virus came from? & $64(32)$ & $136(68)$ \\
\hline The chief mode of transmission of Zika is through mosquito bites & $150(75)$ & $50(25)$ \\
\hline $\begin{array}{l}\text { Maternal/fetal, blood transfusion and sexual transmissions are } \\
\text { other modes of transmissions of zika infection }\end{array}$ & $120(60)$ & $80(40)$ \\
\hline Do you know the symptoms of Zika infection? & $26(13)$ & $174(87)$ \\
\hline Zika, dengue and chikungunya diseases have similar symptoms & $86(53)$ & $114(57)$ \\
\hline People with Zika virus infection require hospitalization? & $128(64)$ & $71(35.5)$ \\
\hline Zika virus can be treated with antiviral agents & $82(41)$ & $118(59)$ \\
\hline A blood or urine test cannot confirm a Zika infection. & $48(24)$ & $152(76)$ \\
\hline Zika virus can be prevented by vaccination & $78(39)$ & $120(60)$ \\
\hline Protective coverings may not be necessary for zika prevention & $50(25)$ & $150(75)$ \\
\hline Zika virus infection in pregnant women causes birth defects & $132(66)$ & $68(34)$ \\
\hline I know an area with zika outbreak & $3(1.5)$ & $195(97.5)$ \\
\hline $\begin{array}{l}\text { Pregnant women and/or those trying to get pregnant should not travel to } \\
\text { places with zika outbreaks. }\end{array}$ & $139(69.5)$ & $61(30.5)$ \\
\hline A pregnant woman can pass zika virus to her fetus & $146(73)$ & $54(27)$ \\
\hline
\end{tabular}

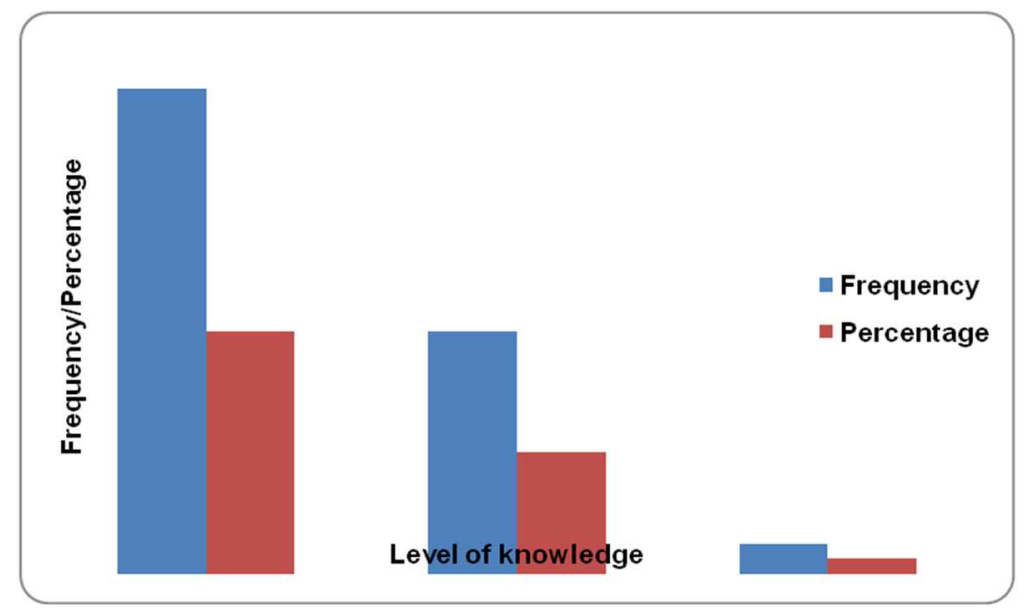

Fig. 1: Level of knowledge of ZIKV infection

Fig. 1 showed that most of the HCPs $(128,64.0 \%)$ had poor knowledge of ZIKV infection. However, among the respondents assessed, the Pharmacists and the Physicians had better knowledge of the disease as the test statistics were statistically significant at $\mathrm{X}^{2}=16.722, \mathrm{p}=0.033$. HCPs in the academia had better knowledge compared to those that are self-employed or practising in private or government hospitals $\left(\mathrm{X}^{2}=17.178\right.$, $\mathrm{p}=0.028$ ) (table 3).

Table 3: The relationship between demographic factors and level of knowledge of Zika virus infection among healthcare professionals

\begin{tabular}{|c|c|c|c|c|c|}
\hline \multirow[t]{2}{*}{ Characteristics } & \multicolumn{3}{|c|}{ Level of knowledge } & \multirow[t]{2}{*}{$\mathbf{X}^{2}$} & \multirow[t]{2}{*}{ p-value } \\
\hline & Poor $(n=128)$ & Fair $(n=64)$ & Excellent $(n=8)$ & & \\
\hline \multicolumn{6}{|l|}{ Gender } \\
\hline Male & $72(67.92)$ & $29(27.36)$ & $5(4.71)$ & 1.849 & 0.397 \\
\hline Female & $56(59.57)$ & $35(37.23)$ & $3(3.19)$ & & \\
\hline \multicolumn{6}{|l|}{ Age (years) } \\
\hline $21-30$ & $24(64.86)$ & $12(32.43)$ & $1(2.70)$ & 5.460 & 0.707 \\
\hline $31-40$ & $36(58.06)$ & $21(33.87)$ & $5(8.06)$ & & \\
\hline $41-50$ & $38(64.40)$ & $19(32.20)$ & $2(3.39)$ & & \\
\hline $51-60$ & $26(72.22)$ & $10(27.77)$ & $0(0.00)$ & & \\
\hline$>60$ & $4(66.67)$ & $2(33.33)$ & $0(0.00)$ & & \\
\hline \multicolumn{6}{|c|}{ Professional status } \\
\hline Physician & $34(58.62)$ & $21(36.21)$ & $3(5.17)$ & 16.722 & $0.033^{*}$ \\
\hline Pharmacist & $36(59.02)$ & $21(34.43)$ & $4(6.56)$ & & \\
\hline Nurse & $45(81.82)$ & $9(16.36)$ & $1(1.82)$ & & \\
\hline
\end{tabular}




\begin{tabular}{llll}
\hline Laboratory Scientist & $11(45.83)$ & $13(54.17)$ & $0(0.00)$ \\
Years of experience & $38(62.30)$ & $19(31.15)$ & $4(6.56)$ \\
$0-5$ & $25(58.14)$ & $17(39.53)$ & $1(2.33)$ \\
$6-10$ & $27(65.85)$ & $11(26.83)$ & $3(7.32)$ \\
$11-15$ & $37(68.52)$ & $17(31.48)$ & $0(0.00)$ \\
$>15$ & $32(84.21)$ & $6(15.79)$ & $0(0.00)$ \\
Place of service & $74(59.68)$ & $43(34.68)$ & $7(5.65)$ \\
Private Hospital & $1(16.67)$ & $4(66.67)$ & $1(16.67)$ \\
Government & $19(67.86)$ & $9(32.14)$ & $0(0.00)$ \\
Academics & $2(50.00)$ & $2(50.00)$ & $0(0.00)$ \\
Self-employed & & & $0.028 *$ \\
Retired & $36(62.07)$ & $20(34.48)$ & $2(3.44)$ \\
Study site & $1(16.67)$ & $4(66.67)$ & $1(16.67)$ \\
UNTH & $28(63.640$ & $11(25.00)$ & $5(11.36)$ \\
UNN & $31(83.78)$ & $6(16.22)$ & $0(0.00)$ \\
UN Medical Center & $9(45.00)$ & $11(55.00)$ & $0(0.00)$ \\
BSH & $23(65.71)$ & $12(34.29)$ & $0(0.00)$ \\
ESUTH & & & $0.003^{*}$ \\
Self-employed & & & 26.920 \\
\hline
\end{tabular}

*significant at $\mathrm{p}<0.05$

\section{DISCUSSION}

Assessment of knowledge of infections and procedures among HCPs have being studied and documented [23]. This study aimed to assess the knowledge of ZIKV infection and its associated factors among health care professionals in some selected health care facilities and institution in Enugu State, Nigeria. Our findings showed that most of the respondents had poor knowledge of ZIKV infection. Sixty-four percent $(64.0 \%)$ of the 200 respondents assessed had poor knowledge of ZIKV infection. However, professional status, place of service and study site was associated with the level of knowledge among the respondents, as the physicians, pharmacists and HCPs in the academia had better knowledge of the infection.

In the present study, overall knowledge of ZIKV infection among Physicians, Pharmacists, Nurses and Medical laboratory scientists assessed was poor. This finding is similar with the reports of previous studies even though they assessed only the Physicians or Dental practitioners $[24,25]$. Unhealthy information seeking behaviour or neglect among health workers may explain their poor knowledge of ZIKV infection as found this study. Other possible explanation could be the ineffective dissemination of information by the media especially during the recent outbreak of ZIKV in Brazil prior to the Olympic Games.

Regarding factors associated with level of knowledge, professional status, place of service, and study site were found to be associated with respondents' knowledge of ZIKV infection. Our result showed that respondents who were Pharmacists or physicians had better knowledge than the Nurses and Medical Laboratory Scientists. This disparity in knowledge could be attributed to better opportunities, access and utilization of medical journals and newsletters, workshop/conference attendance and participation by the former. Additionally, we found that HCPs who are in academia or those that practice in government-owned health facilities had better knowledge compared to those that are self-employed or work in private hospitals and clinics. Surprisingly, a contrary finding was reported in a study conducted in Indonesia, where the authors observed that Physicians in private hospitals had a higher odd of having good knowledge of ZIKV infection compared to those that work in government hospitals [24]. Since most people in Nigeria prefer accessing medical care in government hospitals because it's less expensive and most often have qualified and competent HCPs compared to the private hospital. Hence, HCPs in the government hospital often have firsthand up-to-date information on prevailing disease conditions within and outside the country. Other possible explanation could be because the government routinely sponsors their staff for update seminars, workshop and conferences, which may not be obtainable in most private hospitals.

Furthermore, as expected, HCPs in an academic institution or its environment (University of Nigeria, Nsukka and its Medical Center) were found to have better knowledge of ZIKV infection than those in tertiary, secondary, and private hospitals. Our finding could be because HCPs in the academia or its environment are usually alert to research opportunities, thus are current with recent developments on health issues worldwide.

The HCPs in this study knew that mosquito bite is the chief mode of transmission of ZIKV infection. It is surprising therefore that two third of them did not agree that protective coverings are important preventive measures to take against the infection. Similarly, $60 \%$ of the respondents wrongly chose vaccination as a preventive measure. These findings suggest that the assessed HCPs have poor knowledge of the preventive practices towards contacting ZIKV infection. Literature has shown that avoidance of travel to areas with active ZIKV transmission is one of the best methods of preventing ZIKV infection. Another method is avoiding mosquito bites especially in areas endemic to ZIKV infection. They had good knowledge of the fact that ZIKV infection during pregnancy could cause serious birth defects. Close to $70 \%$ knew that pregnant women and/or those trying to get pregnant should not travel to places with outbreaks. However, only very few knew these places with Zika outbreaks. It is of great concern to note that almost all the HCPs in this study could not recognize the signs and symptoms of ZIKV infection. The majority did not know that Zika, Dengue and Chikunguya diseases have similar symptoms [26]. These findings may imply that even the physicians among them may not be able to make a differential diagnosis of ZIKV infection. However, because of the broadness of the differential diagnosis of ZIKV, the Centers for Disease Control and Prevention(CDC) advice that patients with suspected ZIKV infection should also be evaluated and managed for possible dengue and chikunguya infections. The majority knew that ZIKV infection may not be so serious as to require hospitalization. Greater percentage thought that the infection can be treated with antiviral agents. It is documented that ZIKV infection has no specific treatment options [27]. The symptoms are usually mild and selflimited. HCPs need this information and knowledge to be able to practice effectively. There is an urgent need to advice risk patients to practice safe sex or to abstain from sexual intercourse especially during pregnancy. Physicians need to be educated on the importance of ophthalmic assessments in congenital ZIKV infection. The general public especially the HCPs need to know the importance of protecting people with these diseases (zika, dengue and chikunguya) from further mosquito exposure within the first few days of sickness so as to prevent other mosquitoes from becoming infected thereby reducing the risk of local transmission.

\section{LIMITATIONS}

Our study had few limitations that deserve consideration as it will help in better understanding and interpretation of the implication of its findings. The sample size used was small and disproportionate, hence may not be a true representative of the target population even 
though the respondents assessed had wider coverage of different practice settings. Additionally, our study adopted a cross-sectional design, hence may have the problem of recall bias among respondents as the data was collected at one point in time. Despite this, our assessment has demonstrated that there is an obvious gap in knowledge which can be worked upon to improve local as well as global readiness to combat ZIKV infection.

\section{CONCLUSION}

Our findings suggest that most of the HCPs assessed in this study had poor knowledge of Zika virus infection and that the factors associated with the level of knowledge include professional status, place of service and/or study site. Therefore, awareness programs and seminars geared toward educating HCPs should be supported through the collective effort of well-meaning individuals, nongovernmental organizations, and the government. The media houses also have a significant role to play in sensitization of the entire populace especially during a disease outbreak.

\section{AUTHORS CONTRIBUTIONS}

Akunne M designed the study and contributed in the data analysis. Chukwueke U collected data, Anosike $\mathrm{C}$ wrote the manuscript and also participated in data analysis. All the authors critically revised and approved the final manuscript.

\section{ACKNOWLEDGEMENT}

We are grateful to the healthcare professionals in this study for their willingness to participate.

\section{CONFLICT OF INTERESTS}

We declare no conflict of interest

\section{REFERENCES}

1. McCrae AWR, Kirya BG. Yellow fever and zika virus epizootics and enzootics in uganda. Trans $\mathrm{R}$ Soc Trop Med Hyg 1982;76:552-62.

2. Diallo D, Sall AA, Diagne CT, Faye O, Faye O, Ba Y, et al. Zika virus emergence in mosquitoes in Southeastern Senegal, 2011. PLoS One 2014;9. https://doi.org/10.1371/journal.pone. 0109442.

3. Alera MT, Hermann L, Tac-An IA, Klungthong C, Rutvisuttinunt W, Manasatienkij W, et al. Zika virus infection, philippines. Emerging Infectious Diseases 2015;21:722-4.

4. Kwong JC, Druce JD, Leder K. Zika virus infection acquired during brief travel to Indonesia. Am J Trop Med Hyg 2013;89:516-7.

5. Leung GHY, Baird RW, Druce J, Anstey NM. Zika virus infection in Australia following a monkey bike in Indonesia. Southeast Asian J Trop Med Public Health 2015;46:460-4.

6. Bogoch II, Brady OJ, Kraemer MUG, German M, Creatore MI, Kulkarni MA, et al. Anticipating the international spread of zika virus from Brazil. Lancet 2016;387:335-6.

7. Transmission $W$, Risk H, Risk M, Transmission H, Risk L. List of zika virus-affected countries. Aust Dep Heal; 2016.

8. Yun SI, Lee YM. Zika virus: an emerging flavivirus. J Microbiol 2017;55:204-19.
9. Baden LR, Petersen LR, Jamieson DJ, Powers AM, Honein MA. Zika Virus. N Engl J Med 2016;374:1552-63.

10. D'Ortenzio E, Matheron S, Yazdanpanah Y. Evidence of sexual transmission of zika virus. New England J Med 2016;374:2195-8.

11. Hills SL, Russell K, Hennessey M, Williams C, Oster AM, Fischer $\mathrm{M}$, et al. Transmission of zika virus through sexual contact with travelers to areas of ongoing transmissioncontinental united states. MMWR Morb Mortal Wkly Rep 2016;65:215-6.

12. Musso D, Roche C, Robin E, Nhan T, Teissier A, Cao-Lormeau VM. Potential sexual transmission of zika virus. Emerg Infect Dis 2015;21:359-61.

13. D'Ortenzio E, Matheron S, de Lamballerie $\mathrm{X}$, Hubert $\mathrm{B}$, Piorkowski G, Maquart $\mathrm{M}$, et al. Evidence of sexual transmission of zika virus. N Engl J Med 2016;374:2195-8.

14. Stagg D, Hurst HM. Zika Virus and pregnancy. Nursing for Women's Health 2016;20:299-304.

15. Brasil P, Calvet GA, Siqueira AM, Wakimoto M, de Sequeira PC, Nobre A, et al. Zika virus outbreak in rio de Janeiro, Brazil: Clinical Characterization, Epidemiological and Virological Aspects. PLoS Negl Trop Dis 2016;10. https://doi.org/ 10.1371/journal.pntd.0004636

16. Millichap JG. Zika virus infection and microcephaly. Pediatr Neurol Briefs 2016;30:8.

17. Lucchese G, Kanduc D. Zika virus and autoimmunity: From microcephaly to Guillain-Barré syndrome, and beyond. Autoimmunity Rev 2016;15:801-8.

18. Aggarwal A, Mittal H, Patil R, Debnath S, Rai A. Clinical profile of children with developmental delay and microcephaly. J Neurosci Rural Pract 2013;4:288-91.

19. Passemard S, Kaindl AM, Verloes A. Microcephaly. Handb Clin Neurol 2013;111:129-41.

20. Pithadia AB, Kakadia N. Guillain-barre syndrome (GBS). Pharmacological Reports 2010;62:220-32.

21. Yuki N, Hartung HP. Guillain-barre syndrome. N Engl J Med 2012;366:2294-304.

22. NPC. Nigeria's Population now 182 million. National Population Commission; 2015.

23. Srividya BP, Nagabushan H, Drupad HS. Assessment of knowledge among health care providers regarding intramuscular injection administration. Asian J Pharm Clin Res 2015;8:220-2.

24. Harapan H, Aletta A, Anwar S, Setiawan AM, Maulana R, Wahyuniati $\mathrm{N}$, et al. Healthcare workers' knowledge towards zika virus infection in Indonesia: a survey in aceh. Asian Pac J Trop Med 2017;10:189-94.

25. Gupta N, Randhawa RK, Thakar S, Bansal M, Gupta P, Arora V. Knowledge regarding zika virus infection among dental practitioners of tricity area (Chandigarh, Panchkula and Mohali), India. Niger Postgr Med J 2016;23:33-7.

26. Verma R, Jatav VK, Sharma Sunita. Identification of inhibitors of dengue virus (DENV1, DENV2 AND DENV3) NS2B/NS3 serine protease: a molicular docking and simulation approach. Asian J Pharm Clin Res 2015;8:287-92.

27. Centers for Disease Control and Prevention. Available from: https://www.cdc.gov/zika/hc-providers/preparing-for-zika/ clinicalevaluationdisease.html. [Last accessed on 29 Aug 2017]. 